Historic, Archive Document

Do not assume content reflects current scientific knowledge, policies, or practices. 



\section{How to Grow the Tomato And 115 Ways to Prepare it for the Table}

By

G. W. GARVER, M. S . Aggr.

Director 
To my esteemed friend and co-worker, Mrs. Adella Hunt Logan, who was tireless in her efforts to help the farmer and his family, and who saw in the tomato a panacea for many of his ills; and who contributed more data of real value along this line than anyone else with whom I have come in contact, I affectionately dedicate this bulletin. 


\title{
How to Grow the Tomato and 115 Ways to Prepare it for the Table
}

\author{
By G. W. Carver
}

But few people realize what an important vegetable the tomato is. While it is true that chemical analysis does not place it very high in the nutritive scale, if viewed from this angle alone its real value will be greatly underestimated.

For the reasons which follow, every normal person should mahe the tomato a very prominent part of the weekly diet:

1. It is a vegetable that is easily grown.

2. It yields well and keeps for a long time.

3. It usually brings a fair price, because nearly everyone likes tomatoes.

4. It contains distinct medicinal virtues (which are recognized by many authoritative books on household remedies), as "vegetable calomel."

5. It is both a relish and an appetizer as well as a food.

6. Our soils can be made to bring enormous yields of tomatoes, superior in look, taste, and general appearance.

7. They can be prepared in so many delicious ways that one can eat them every day in the week and not get tired of them.

8. The old vines contain splendid dye-stuffs, which could be utilized as a by-product for dying fabrics of various kinds.

9. There as so many sizes, colors, and varieties that, for garnishings, fancy soups, and especially fine decorative table-effects, they are almost indispensable.

10. With a little intelligent effort fresh tomatoes can be produced in this locality almost the year round.

\section{SELECTION OF SOIL}

The tomato is not at all choice in the kind of soil in which it grows; in fact, almost any well-drained soil can be made to produce good tomatoes. However, for early ripening, it shows a preference for a light, loamy soil; and, if very early tomatoes are desired, the soil must be only moderately rich, as a highly-fertile soil produces large vines and more fruit, which is likely to delay ripening of the tomatoes. 


\section{PREPARATION OF THE SOIL}

It is most essential that the ground be spaded or plowed up very deep, harrowed and re-plowed if necessary, until every large clod is mashed, and the ground is fine and mellow.

Do not plant tomatoes on land that has had white potatoes, melons, or tomatoes on it the year previous. Indeed, it is best to let the land rest from these crops three or four years, as all of them are subject to the same blight disease.

\section{FERTILIZERS}

It is a mistake to think that the tomato does not like a rich soil. Indeed, to have the best tomatoes, the soil must be rich. The plant is very partial to a soil full of well-rotted vegetable matter; hence, we recommend the following fertilizers, based upon experiments carried out here on the Experiment Station grounds, which gave excellent results:

Two loads of leaves from the forest and muck from the swamp were spread over the bottom of a pen; then one load of barnyard manure. This was continued until the pen was full, and rounded over at the top like a potato-hill, so as to prevent the excess of water from washing out the fertilizing constituents. To this heap old rags, plaster, lime, paper, wood-ashes, finely-beaten-up bones, etc., can be advantageously added.

Make this compost heap in the fall so it will be well rotted by spring.

\section{STARTING THE TOMATO PLANT*}

In the northern part of West Virginia and in the higher altitudes the tomato seed should be sown from the first to the fifteenth of March, but in the southern part and along the Ohio and Kanawha rivers the seed may be sown as early as February fifteenth.

The best method of starting the plants is by use of a hotbed. It may be constructed as follows: Select a well-drained location where the bed will be sheltered, preferably on the south side of a building or fence. Dig a pit 3 feet wide by 6 feet long and 2 feet deep, so that the long side faces the south. Line the inside of the pit with boards. A stake may be driven in at each corner to serve as a support for the frame, if boards cannot be obtained for the lining. Fill the pit with fresh horse manure well packed down by tramping. Construct a frame 3 feet wide by 6 feet long. Have this frame 12 inches high at back or north side and 6 inches high at the

*Note-The above directions for starting the tomato plant are taken from the Extension Department of West Virginia University, Sheet No. I. 
front or south side. Place the frame over the pit and bank the outside with strawy manure or soil.

Place in the frame four or five inches of good garden loam which has not grown any diseased plants. Cover the bed with glass hotbed sash. Unbleached muslin or cheesecloth may be substituted for the glass.

The fresh horse manure is used to furnish heat for the plants. No seed should be planted until the temperature of the soil falls to 80 degrees $\mathrm{F}$.

If a crop of tomatoes for early market is desired, transplanting is necessary. In this case use two or three rows across the end of the hotbed for sowing the seed, and use the remainder of the bed for transplanting.

Mark off rows from three to six inches apart and one-fourth inch deep. Drill in the tomato seed, about 12 seeds to the inch. Level the soil and press the surface of the bed firmly and uniformly. Moisten the ground thoroughly.

During summer days ventilate by raising the cover a few inches on the side opposite the wind. Toward evening close the sash in order to get the bed warm before night. As the plants grow older the ventilation may be increased. Water in the mornings on bright days only. Keep the bed moist but not wet. Ventilate after watering in order to dry off the plants.

When the seedlings are about two inches high, or just before the second leaves set, transplant them two inches apart each way to another part of the bed. Another transplanting four inches apart should be made in about three weeks. If there is no remaining space in the hotbed, a cold frame, constructed similar to the hotbed except that no pit or manure is necessary, may be used. The seedlings may be transplanted to small boxes or flats about 18 inches long, 12 inches wide, and $2 \frac{1}{2}$ inches deep and then the boxes placed in the hotbed or the cold frame.

If the tomatoes are to be canned, principally, it is not necessary to hasten the maturing of all the plants. In that case the hotbed may be used without any transplanting. Mark off rows four inches apart and one-fourth inch deep. Place one seed every two inches in the row and then transplant every other seedling to another part of the hotbed or place the seeds at distances of four inches and do not transplant. Allow these to grow as they stand, until ready for the field.

Before the seedlings are set in the garden plot they should be hardened off by a scant supply of water for several days and by the absence of any covering at night, when there is no danger of frost. Moisten well just before transplanting. 


\section{STARTING THE SEED}

For a family garden, saw an ordinary cracker-box half in two so it will not be more than six or seven inches deep; nearly fill with good, rich earth; sow the seed; sift earth over them until well covered; water thoroughly, and set in a sunny window. They will soon come up and grow off rapidly. Set out doors on warm days to make them hardy, strong, and stalky.

For a later planting sow out of doors, in this latitude about April 15 th.

\section{SETTING THE PLANTS}

Lay off rows with a middle-burster or two-horse plow; put well rotted compost in drill at the rate of 25 tons to the acre; bed upon it lightly, and set the tomatoes directly upon it.

Where a chemical fertilizer is used aim at the following:

Cottonseed meal .................. $800 \mathrm{lbs}$.

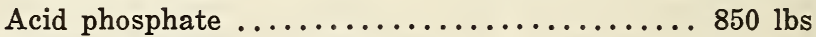

Nitrate of soda .................. $50 \mathrm{lbs}$.

The nitrate of soda to be applied as a top dressing. Just as the tomatoes begin to set, 250 pounds of muriate of potash is desirable, but at present it is out of the question. For this reason I strongly urge the compost.

\section{SELECTION OF VARIETIES}

Every year adds to the long list of varieties of the tomato. With many of these so-called varieties there is a distinction with but little or no difference.

The following varieties have done exceedingly well here on our trial grounds:

Extra Early Varieties: Spark's Earliana, June Pink, Burpee's Earliest Pink, John Baer, Prosperity, Bolgian's I. X. L., and Chalk's Early Jewel.

Mid-Summer Varieties: My Maryland, Greater Baltimore, Dwarf Champion, and New Stone.

Late Varieties: Red Rock, Acme, Livingstone's Stone.

\section{CULTIVATION}

Tomatoes like the soil about them kept loose and mellow by frequent hoeings, and at no time must they be allowed to become weedy, as weeds greatly injure the plants. A little commercial fertilizer or a quart of compost dug in around the vines once per month will give finer tomatoes and prolong the life of the vines. 
Caution-Do not use fresh or unrotted manure, as it encourages diseases of various kinds.

\section{PRUNING}

When extra early tomatoes are desired it is important that the pruning be done properly.

1. Train the vine to one or two stalks.

2. Tie to stakes well sharpened and driven into the earth. Tie the vines securely to these stakes at frequent intervals.

3. Keep growing vigorously until the lower fruit is half grown; then cut off the top just above the larger fruit. This will cause the fruit to ripen several days earlier than if the top was left on.

It is important to note that, as a rule, 90 per cent of the tomatoes grow within 18 or 20 inches of the ground, although the vines grow much taller; hence, the wisdom of pruning.

\section{ROOTING CUTTINGS}

In this locality July and August are the best time to root tomato cuttings. The tops and suckers will root readily if inserted in boxes of moist sand or moist shady places. The cutting should be 3 or 4 inches in length. Keep well watered, and they will be nicely rooted in about 9 days, when they should be taken up and set the same as for seedlings. They will begin bearing almost as soon as they begin growing well. They are preferable to seedlings.

In making the cuttings half of each large leat should be taken off.

\section{EXTENDING THE SEASON}

Method No. 1.-Just before the first frost pick the large, well-developed green tomatoes, and place them side by side in a cool, dry place. Do not let them touch each other. Care must also be taken not to bruise them. Straw or dry leaves can be placed in a coldframe, and the bed filled with them.

Method No. 2.-Pull up the whole vine, fruit and all; hang the vines top-downward in a cool, dry place. In this way nice, ripe tomatoes can be had until Christmas, New Year, or even later.

\section{FUNGUS DISEASES}

The most serious diseases affecting the tomato in this locality are these:

Leafspot Disease (Septoria lycopersici).-This trouble covers the 
leaves with minute brown specks, after which they turn yellow and fall off, causing the plant to die outright or become unfruitful.

Remedy.-Spray the plants as directed with the following mixture just as soon as the first signs of the disease appear:

\section{Bordeaux Mixture}

(By F. E. Meyers \& Bros.)

Copper Sulphate (blue vitriol) .......... lbs.

Quicklime (not air-slaked) .............. lbs.

(Of dry air-slaked lime or hydrate of lime onefourth more.)

Water to make ..................50 gals.

Dissolve the copper sulphate by putting it in a bag of cheese-cloth and hanging this in a vessel holding at least 4 gallons, so that it is just covered by water. Use an earthen or wooden vessel. Slake the lime by addition of a small quantity of water, and when slaked cover freely with water and stir. Strain the milk of lime thus made into the copper sulphate. Pour more water over the remaining lime; stir and strain into the other until all lime but stone lumps is taken up, and then add sufficient water to make 50 gallons in tank. Thoroughly agitate mixture, when it will be ready to apply. The mixture should be made fresh before using, and any left over for a time should be thrown out or have fresh lime added. The above is the 4-4-50 formula. Can be used up to 6-6-50 just before bloom on apples or potatoes.

The above is for rots, molds, mildews, and all fungous diseases.

\section{BLACK MOULD (Macrosporium tomato)}

This disease attacks the tomato itself, beginning at the blossom end. Tomatoes with rough skins and crushed ends are more likely to take the disease than the smooth skinned varieties; hence, the wisdom of selecting smooth skinned varieties.

Fruits that lie upon the ground and those grown in dense shade are affected worst; which emphasizes the importance of staking the vines and pruning so as to let the sun in.

ANTHRACNOSE (Colletotrichum phomoides)

This is another very destructive disease of the fruit. Treat the same as for black mould. 


\section{TOMATO WILT (Sclerotium Rolfsii)}

This is a very troublesome disease to many plants, and one of the worst the tomato-grower has to fight.

Symptoms-It makes. its appearance similarly to the cotton wilt and frequently destroys whole fields within a short time, if neglected.

(a) It is worst during wet, cloudy weather.

(b) Coarse, unrotted manure encourages its growth.

(c) Planting too thick so the sun can't get to the soil.

It is easily recognized by a fine white mold just above the ground, later this mould is followed by great masses of white and brown seed-like bodies-by this time, however, the plant is hopelessly involved.

Remedy-Avoid the use of (a), (b), and (c) ; and since the disease appears just at the surface of the ground, it is wise to scrape the earth away quite to the large roots, keeping it away during wet weather. All vines should be staked up off the ground.

As soon as the earth dries out to good growing conditions of moisture, return the earth about the roots. A liberal amount of wood ashes with the soil seems to have proven beneficial.

\section{FUSARIUM WILT (Fusarium lycopersisi) BACTERIAL Wilt (Bacillus solanacearum)}

Both of the above diseases at times are quite troublesome, and work within the plant, making sprays of all kinds useless.

The best remedy to date is:

1. Good clean seed, free from blight.

2. Rotation of crops.

This same disease attacks tobacco, eggplants, and peppers; therefore do not let your tomatoes follow these crops. Keep them off these infested areas for at least three years, five years would be better.

\section{BLOSSOM-END ROT OR POINT ROT}

This is a very destructive disease of the fruit, appearing as a dry, black spot, starting at the blossom end.

Remedy-It appears worst during dry, hot seasons; hence, we recommend absolutely clean cultivation and a dust mulch all the time, to encourage both the using and saving of the moisture. 
FRUIT ROT, SOFT ROT, ETC. (Phoma destructiva Plowr)

This disease is destructive to both leaves and fruit, causing a spotting, and if neglected, will cause them both to drop off.

Remedy-Spray with Bordeaux mixture.

\section{INSECT ENEMIES}

There are at present only a few insect enemies of the tomato that causes much concern in this locality:

1. The "tomato worm," the "corn ear worm," the "boll worm," etc.

This insect often does serious damage by boring into and destroying the small green tomatoes, in fact, it is the corn-ear worm of the North, and the cotton-boll worm of the South.

Remedy-Plow all corn land in the fall as the insects winter over in the ground.

Pick off, and destroy the punctured tomatoes. Cultivate frequently and keep the plants growing.

\section{COLORADO POTATO BEETLE}

This beetle is often very troublesome, but can be held in check or completely exterminated by poisoning with Paris green or arsenate of lead.

SPHINX CATERPILLAR, "HAWK MOTH," ETC.

This insect makes the large, obnoxious green worm, so common on tomato vines. Hand-picking is the best remedy, but spraying with arsenate of lead or Paris green will kill them.

ARSENATE OF LEAD

By F. E. Myer Brothers

Arsenate of Soda $\ldots \ldots \ldots \ldots \ldots \ldots$ ounces

Acetate of Lead ................11 ounces

Water $. . . \ldots \ldots \ldots \ldots \ldots \ldots . . .6$ to 5 gallons

Dissolve the ingredients separately each in one gallon of warm water. Mix, and pour into spray tank containing from 50 to 100 gallons of water. Add the milk of lime from two or three pounds of freshly slacked lime. This is the most satisfactory mixture of any for the formula. It is more adhesive than Paris green, and if properly made of good materials will burn foliage but little, no matter what strength 
is used. In some respects the commercial brands on the market are more satisfactory than the home-made product. For most purposes three pounds of the commercial product, arsenate of lead, in 50 gallons of spray are used. Either water or Bordeaux mixture may be used as the carrier.

\section{Paris Green}

Paris green may be used with Bordeaux mixture at the rate of one pound in from 100 to 150 gallons. It may be used alone in water in the same proportion with two or three pounds of freshly slacked lime added to prevent burning of the foliage. The mixture should be kept well stirred.

\section{PREPARATION FOR THE TABLE}

As before stated there are but few garden vegetables from which such a large number of attractive, wholesome, and nutritious dishes can be made, and it is hoped that the large number of recipes given below will encourage the housewife to serve this choice vegetable many times during the week, and each time the consumer consider it a luxury.

Macaroni and Tomatoes, No. 1

Cook the required amount of macaroni in plain water to which a little salt has been added; cook till soft; cut a small piece of salt pork into little pieces; one small onion sliced; put into a frying pan and brown. Drain the water off the macaroni; pour into the frying pan; add enough tomato paste to season well; add pepper and a bit of cheese if desired.

\section{Macaroni and Tomatoes, No. 2}

Use either macaroni or spaghetti; prepare the sauce as for No. 1; season to taste with salt, pepper and butter; make rich with tomatoes (either fresh or canned) cooked to a pulp; put the mixture, layer by layer, into a baking dish, grating a thin layer of cheese over each layer, covering the cheese with buttered bread crumbs; return to the oven and bake 25 minutes.

\section{No. 3-Stewed Tomatoes}

Scald; peel and cut into small pieces; cook quiickly, stirring frequently until free from lumps; add $1 / 4$ cup of sugar or sweeten to taste; two tablespoons butter; $1 / 2$ teaspoon salt; $1 / 8$ teaspoon pepper; 
a small onion sliced and a pod of green pepper. Cook slowly for ten minutes more and serve hot.

\section{No. 4-Tomatoes Broiled}

Wipe; scald; peel and cut the tomatoes in halves or thick slices; if very large lay on a wire broiler; when hot, add a pinch of pepper, salt and a bit of butter; toast quickly until brown; serve hot.

\section{No. 5-Stuffed Tomatoes}

Select firm, well-ripened tomatoes; remove stem end; take out about two-thirds of the pulp; mix the juice and pulp with the filling; for six tomatoes allow $1 / 2$ cup of cold meat or fish chopped fine; add $1 / 2$ cup of mashed peas, beans, grits, rice, potatoes or soft bread crumbs, 1 onion minced fine or parsley, celery, etc. Salt and pepper to taste; fill the cases; cover with well-buttered bread crumbs; place them in buttered pan, and bake from 20 to 25 minutes in a moderate oven.

\section{No. 6-Baked Tomatoes}

Cut in halves; lay them in buttered pan; cover with buttered bread crumbs, and bake till brown.

\section{No. 7-Cream of Tomato Soup}

Peel and chop to a pulp one pint of very ripe tomatoes, or one can will do, add 1 qt. milk; $1 / 4$ teaspoon pepper, sprig or parsley, $1 / 4$ teaspoon soda, 1 teaspoon salt, 2 tablespoons butter, 1 teaspoon sugar, 1 tablespoon flour. Add all of the flavorings to the tomatoes, and cook for 10 minutes; rub through a colander; heat the milk to the boiling point; thicken with the flour and butter rubbed to a paste; re-heat the tomatoes and add the soda; stir all together and serve at once with bits of toasted. bread.

\section{No. 8-Plain Tomato Soup}

Use the quantity of tomatoes as recommended for No. 7; add 1 teaspoon salt, 4 teaspoons flour, 4 tablespoons butter, $1 / 4$ teaspoon pepper, 1 teaspoon salt, 1 qt. water, 1 onion chopped fine; mix the water, tomatoes, and seasonings; heat to the boiling point; add butter and flour rubbed to a paste and cook for a few minutes; strain and serve with bits of toasted bread. 


\section{No. 9-Tomato Sauce}

Cook for 10 minutes one pint of tomatoes peeled and chopped or canned; put through a sieve; melt 4 tablespoons butter; rub in 4 tablespoons flour; add 1/2 teaspoon salt, 1/8 teaspoon pepper; add the tomato, and cook until it thickens.

\section{No. 10-Tomato and Okra Soup}

Take $1 \frac{1}{2}$ pints of tomatoes pared and cut fine; 2 qts. water; 1 large onion minced fine; 3 tablespoons rice; 1 green pepper with seeds removed and minced fine; 3 teaspoons salt; $1 / 4$ teaspoon black pepper. Mix all the ingredients; put into a soup pot, and cook gently for two hours; add two tablespoons butter and serve.

\section{No 11-Tomatoes Spanish Style}

Peel and slice 1 quart of tomatoes (or use one 3-1b. can). Remove seeds, and cut in small pieces 3 bell peppers; boil till tender 4 onions; add tomatoes and peppers to onions, and simmer 1 hour; season with 2 level teaspoons salt and 1/2 teaspoon black pepper; cool, and keep on ice for several hours. Prepare two cups of stale bread crumbs; take 6 tablespoons of butter, lard or Wesson Snowdrift oil. Fill a baking dish with alternate layers of tomatoes and bread crumbs; moisten each layer with oil; cover top with bread crumbs, and bake in a slow oven for 1 hour. If desired 3 tablespoons of sugar may be added to the mixture while it is cooking the first time.

\section{No. 12-Breaded Tomatoes}

Scald and skin the desired number of tomatoes; remove hard ends and cut into small pieces; stew in porcelain stew-pan till tender; add salt, pepper, and sugar to taste, also one teaspoon butter to each pint of pulp; thicken with coarse or fine bread crumbs, or thicken with a little flour dissolved in cold water, or serve plain as desired.

\section{N. 13-Tomato Catsup}

Take 1 peck of thoroughly ripe tomatoes and cook slowly, without water, until tender; rub through a colander; return to the fire and boil until thick; stir almost constantly to keep from burning. Now add 1 pint of vinegar, 1 pound of sugar, 2 tablespoons black pepper, $1 / 2$ teacup of salt, $1 / 2$ tablespoon Cayenne pepper. Boil again until thick; pour at once into well-sterilized bottles, and seal or cork tightly; set in a dark, cool place. 


\section{No. 14-Tomato Goulash}

Take 1 pint of fresh or canned tomatoes, 2 pounds of lean beef cut into small strips, 3 large onions, sliced, 2 tablespoons drippings, 1 pint of shredded cabbage, 7 small potatoes, 1 teaspoon salt, 1 teaspoon paprika, 1 cup of water, and 1 cup of milk. Place the drippings in a kettle; when smoking hot add the meat; when the meat is brown remove from the kettle, and put in the onions and cabbage; then put in the meat and the tomatoes; add the seasonings and the water; cook very slowly until the meat is tender; then add the potatoes; when they are done add the milk; boil up once and serve.

\section{No. 15-Baked Tomatoes with Cheese}

Select nice large tomatoes; peel with a sharp knife; make a cavity in the end of each, and press a piece of cheese into each one-press three or four small pieces into the sides of each tomato; press a bit of butter into each; salt and pepper the tomatoes to taste, and at the side of each one lay a piece of cheese the size of a walnut. Cover with bread crumbs; bake in a moderate oven $1 / 2$ hour if the tomatoes are medium size and 1 hour if very large; baste them several times with the liquid that forms. Little water is needed, as they will form their own liquor. When done, brown them nicely on the top and serve at once.

\section{No. 16-Tomatoes as Olives or Vermont Olives}

Take a bushel of green and half-ripe tomatoes (the plum or fig tomatoes are preferable); wash clean; pack in big jar or tub; use $5 \mathrm{lbs}$. fine salt, $1 / 2 \mathrm{lb}$. whole mixed spices; weight down and cover with clear cold water. In two weeks they are fit to use, and will keep for months if kept under the pickle. They are used without further fixing.

\section{No. 17-Tomatoes with Cream Dressing}

Take the required number of nice, smooth, ripe tomatoes; remove the skins; make a hollow at each stem end; stand on ice until thoroughly chilled. For the dressing allow to the yolks of three hard-boiled eggs, one raw yolk, one tablespoon of melted butter, two tablespoons vinegar, one gill of thick cream, one-half teaspoon of pepper. Mash the boiled yolks until fine, then work them smooth with the raw yolk; add the pepper and melted butter; salt to taste; then little by little add the cream, working and mixing all the time; lastly stir in the 
vinegar; blend thoroughly. Drop a spoonful into the hollow of every tomato, and serve in a crisp lettuce leaf.

\section{No. 18-Puree of Tomatoes}

Take one pint of canned or finely-chopped fresh tomatoes, one cup of water, one teaspoon of chopped green peppers, two tablespoons sugar, one teaspoon salt, two level tablespoons butter, the same of flour; strain the tomatoes, and rub the pulp through a sieve; add the water, pepper, sugar, and salt, and put over fire; rub the butter and flour to a smooth paste, and stir it into the tomato stock as it heats; boil flve or ten minutes, and serve with bits of toasted bread (croutons).

\section{No. 19-Tomato Sauce, No. 2}

Use $1 / 2$ can tomatoes, 1 tablespoon flour, 3 cloves, 2 tablespoons butter, $1 / 4$ teaspoon black pepper, 1 bay leaf, 1 teaspoon chopped parsley, $1 / 2$ teaspoon salt, 1 tablespoon chopped onion. Place 1 tablespoon of the butter in a saucepan; add the flour, and cook 5 minutes, stirring constantly; then add the tomatoes, salt, pepper, bay leaf, and cloves; cook until thick and smooth; add by little pieces the second spoonful of butter; cook slowly for 5 minutes longer; strain and serve.

\section{No. 20-Tomatoes with Eggs}

Season two cupfuls stewed tomatoes with salt, butter, pepper, and one onion sliced thinly; break six or more eggs into the cold tomatoes; cover with bread crumbs; drop bits of butter freely over the top; set in the oven and bake until the eggs are set; serve with boiled rice or macaroni or hot, dry toast.

\section{No. 21-Tomatoes Smothered with Beef Steak}

Cut the beef steak in convenient pieces for serving; season with salt and pepper; roll in bread crumbs; put at once into a hot frying-pan, in which are two tablespoons of butter and drippings mixed; brown quickly on both sides; pour over the steak two cups of boiling-hot, well-seasoned tomatoes; cover and cook in a hot oven until thoroughly done.

\section{No. 22-Tomatoes Smothered with Pork Chops}

Select nice pork chops, and proceed exactly the same as recommended for beef steak (No. 21). 


\section{No. 23-Tomato Fritters}

Prepare enough nice, ripe tomatoes to make one quart when stewed; cook with them one small onion, a few cloves, and two tablespoons sugar; cook thoroughly; strain through a sieve; season to taste with salt and pepper. To one-fourth cupful of butter, bubbling hot, add one-half cupful of corn starch; to this add the tomatoes you have already prepared with onion, cloves, and sugar, stirring them in gradually; cook about three minutes or until blended; then add one egg slightly beaten. Put this in a shallow buttered tin, and when cool cut into squares; roll in bread crumbs, egg, and then crumbs again, and fry in deep fat; drain before serving.

\section{No. 24-Tomatoes and Corn}

Wash, peel, and stew the required amount of tomatoes until rather thick; add salt and pepper to taste, a generous lump of butter, one teaspoon sugar; split the grains and scrape the corn from six ears, or aim to get just as much corn as tomatoes; cook until well done; serve hot.

\section{No. 25-Tomato and Rice Soup (Very fine)}

Brown carefully in a sauce-pan one tablespoon butter and the same of minced onions; when a golden brown add a quart of peeled and chopped tomatoes; cook thoroughly; pass through a sieve to remove the seeds and hard lumps. Add the tomatoes to two quarts of beef stock; when boiling hard, add $1 / 2$ cup of rice; cook until the rice is soft; chop up very fine or run through a meat-chopper some of the meat, and add to the soup; season to taste with salt and pepper.

\section{No. 26-Tomato Conserve}

To be used in soups, stews, and may be diluted for sauce.

Put in an earthen stew-pan as many sound, ripe tomatoes as desired; cook slowly until the skins come off easily; strain through a hair sieve, pressing gently with a wooden spoon; throw away the first water that passes through the sieve. Return to the stew-pan, adding a dessertspoon of mixed spices to each pound of tomatoes; salt to taste. Cook slowly until very thick; if to be kept only a short time put in wide-mouthed bottles; stand the bottles in a kettle of water like any other preserve; boil for 15 minutes; cool, cover, and set in a cool, dark place. It may be put boiling-hot into sterilized glass jars, and sealed the same as any fruit jar. In this way it will keep indefinitely. 


\section{No. 27-Stuffed Tomatoes, Italian Style}

Take

6 nice ripe tomatoes,

2 ounces of bread crumbs moistened with vinegar,

1 ounce cheese, grated.

4 eggs and a small wisp of parsley.

Cut the stem end off the tomatoes; remove the core and seeds, and fill with the following mixture: Add the bread crumbs, cheese, and two of the eggs boiled hard and finely chopped, a dessertspoon of finely chopped herbs (basil or savory); pepper and salt to taste; mix well with the other two eggs well beaten; fill the tomatoes with the mixture; cover the top of each tomato with bread crumbs mixed with finely-chopped parsley; put a small piece of butter on each, and put on a greased baking pan; cook in a slow oven for 20 or 30 minutes.

\section{No. 28-Panned Tomatoes}

Put into a pan with two ounces of butter six firm but well-ripened tnmatoes that have been cut into halves; cook slowly on top of the stove for 15 minutes; brown quickly in a hot oven. Remove the tomatoes to a hot platter, and make a sauce by adding to the browned butter two tablespoons flour, rubbing until smooth; add one pint of rich milk; stir until it boils; season with salt and pepper, and pour over the tomatoes; garnish with parsley and bits of toast.

The above is greatly relished with roast meats.

\section{No. 29-Scallop of Tomatoes and Potatoes}

Peel and chop one-half pint of tomatoes; season to taste. with salt, pepper, and onion juice. Prepare the same amount of potatoes and in the same way; mix thoroughly. Butter a baking dish, and sprinkle with bread crumbs, and put in half the tomatoes; then a layer of soft crackers or bread crumbs that have been well buttered; cover with two heaping teaspoons of grated American cheese; then the other layer of tomatoes; cover with buttered crumbs; place in a hot oven, and bake 25 minutes; serve at once.

\section{No. 30-Fried Green Tomatoes}

Cut both stem and blossom end from large, green tomatoes; cut in thin slices; roll in flour, and fry in hot butter. Sprinkle with salt, pepper, and a little sugar; cook until brown. A little onion may be fried with them if desired. 


\section{No. 31-Creamed Tomatoes}

Cut in thick slices as many thoroughly ripe tomatoes as desired; fry until tender in hot butter, and then set on a hot platter in the open oven. Stir a tablespoon of flour into the butter in the pan until well blended. Let it cook until creamy; then stir in a cup of very rich milk, in which a pinch of soda has been dissolved. Stir and cook to a smooth sauce; season with salt and pepper to taste, also a little curry powder if you wish; pour over the tomatoes and serve.

\section{No. 32-Curried Tomatoes}

Put in the frying pan a heaping tablespoon of butter and half an onion minced; cook two or three minutes; then stir in a scant teaspoon of curry powder; cut the tomatoes in slices and fry brown in the seasoned butter; sprinkle with salt, and serve at once on a hot platter.

\section{No. 33-Green Tomato Jam}

Take $4 \mathrm{lbs}$. of green tomatoes, $4 \mathrm{lbs}$. of loaf sugar, 1 cup water, and 2 ounces of preserved ginger. Wash tomatoes and cut in pieces; add remaining ingredients and cook until clear, which will require about two hours. Strain through a coarse strainer to remove the seeds. Pour boiling-hot into sterilized jars, and seal.

\section{No. 34-Green Tomato Soup}

Take 4 green tomatoes just beginning to ripen, one large onion; slice all together; cover with salted water, and cook until done. Add one cup of milk and two cups sweet cream. Serve at once with crackers, croutons, or bread sticks.

\section{No. 35-Tomatoes Stuffed with Corn (Delicious)}

Remove the top and scoop out the centers of smooth, well-ripened tomatoes; cut some tender corn from the cob; put through the fine knife of a meat-grinder; season with pepper, salt, and a little sugar. Fill the cavities of the tomatoes, and pour a teaspoon of melted butter on top of each tomato; bake in a hot oven until soft, which will require from 15 to 20 minutes.

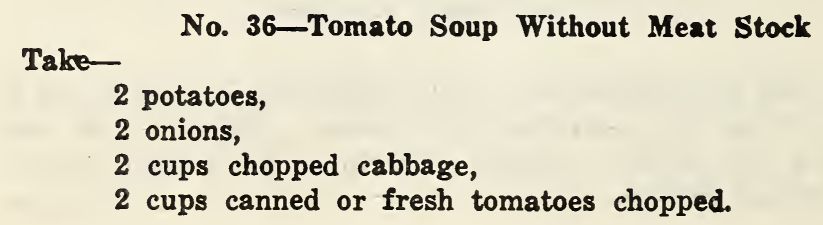


Put on the fire in a granite or porcelain kettle with plenty of cold water; season with salt, pepper, and butter; serve with crackers or croutons.

\section{No. 37-Tomato Jam (Very rich)}

Take 7 pounds of ripe tomatoes after they are peeled, 3 pounds of sugar, 1 pound of seeded raisins, 1 pint of vinegar, 1 lemon (cut fine), 2 teaspoons cinamon, the same of ground cloves, and a touch of Cayenne pepper. Boil until it gets thick like jam; pour into glasses or crocks, and seal with paraffin. This is delicious served as a relish with hash or cold meat.

\section{No. 38-Tomato Chilli Sauce, No. 1}

Take $1 / 2$ peck of green tomatoes, half as much each of onions, and hot, green peppers; peel the tomatoes and onions, and chop fine. Cut the peppers, removing the inner white skin, and chop, leaving in the seeds; add one cup of salt, two cups of sugar, and one quart of vinegar. Boil the mixture for about three hours, or until it thickens a little; pour into well-sterilized bottles, and seal hot.

\section{No. 39-Tomato Cold Relish}

\section{Take-}

1 peck of ripe tomatoes that have stood chopped over night,

4 hot green peppers, seeded and chopped,

2 cups of chopped celery,

5 ounces of white mustard seed,

5 large onions chopped fine,

$1 / 2$ cup of salt,

4 cups brown sugar,

5 cups vinegar.

Stir the ingredients together, pack cold in glass jars, cover with the liquor, drop $1 / 2$ dozen cloves on top, and seal. Set in 2 dark, cool place.

Take-

\section{No. 40 - French Pickled Tomatoes}

1 peck of green tomatoes, sliced,

6 large onions,

1/2 cup of salt sprinkled on mixture.

Let this stand over night; drain thoroughly in a colander; add two quarts of water, one of vinegar; boil 15 minutes. Take out and drain; add 4 quarts of vinegar, 2 pounds of sugar, and $1 / 2$ pound white mustard seed. Tie in a muslin bag one tablespoon each of all 
kinds of spice, and add to the mixture; stir thoroughly, and boil until tender; put in stone jars; cover tightly, and set in a cool, dry dark place.

\section{No. 41-Tomato Ketchup}

Take-

2 quarts of tomatoes, sliced,

2 onions, sliced. Cook together and rub through a sieve. Add the following ingredients:

2 cups vinegar,

2 cups sugar,

1 tablespoon mustard,

1 tablespoon of cloves,

1 tablespoon cinnamon,

1 tablespoon salt,

1 tablespoon pepper.

Cook one hour, bottle, and seal.

\section{No. 42-Tomato Jelly}

\section{Take-}

$1 / 2$ can of tomatoes,

$1 / 2$ teaspoon thyme,

1 teaspoon salt,

1 teaspoon sugar,

1 bay leaf,

1 small onion,

3 cloves,

$1 / 2$ box of gelatine soaked in $1 / 2$ cup of water.

Boil all together till the tomatoes are soft; then add the gelatine, and stir until it is dissolved; strain and pour into a mold.

\section{No. 43-Tomato, Cabbage, and Onion Pickles}

\section{Use-}

1 gallon of green tomatoes,

1 medium-sized head of cabbage, chopped fine,

12 medium-sized onions, sliced,

1 quart of vinegar,

1 cup sugar,

1 teaspoon mixed spices.

Cook the cabbage, onions, and tomatoes separately until done; drain each one well; put them all together; add the sugar, vinegar, and spices; boil ten minutes; pour into sterilized glass jars, and seal. 


\section{No. 44-Tomato Catsup, No. 1}

Take-

$1 / 2$ bushel of ripe tomatoes, pared,

1 quart vinegar,

$1 / 2$ pint salt,

1 tablespoon cloves,

1 tablespoon ginger,

1 tablespoon cinnamon,

2 tablespoons mustard,

2 tablespoons black pepper,

2 tablespoons allspice,

$1 / 2$ teaspoon Cayenne pepper.

Cook the tomatoes until very soft; press through a fine sieve to remove the seed; return to the kettle, and cook as thick as you desire the catsup. Now add all the other ingredients; cook 10 or 15 minutes longer; pour into sterilized bottles and cork tightly. No further sealing is necessary; it will keep for years.

Take-

\section{No. 45-Tomato Catsup Uncooked, No. 2}

1 peck of ripe tomatoes, peeled and chopped,

4 bunches of celery, chopped fine,

1 large cupful chopped onion,

$1 / 4$ cup salt,

$1 / 4$ cup sugar,

2 tablespoons mustard seed,

2 tablespoons ground cinnamon,

1 teaspoon ground allspice,

2 large red peppers,

$1 / 2$ teaspoon Cáyenne?

Put the chopped tomatoes in a bag and let drain 24 hours; add the celery and the onion; mix thoroughly; add the salt; add all the other ingredients; mix very thoroughly; cover with good strong vinegar; put in glass jars and seal.

\section{No. 46-Egg Tomatoes in Sweet Pickle}

Take 7 pounds of egg or cherry tomatoes, scalded and peeled; cover them with vinegar much diluted with water, and let stand 12 hours. Put $1 / 2$ cup of weak vinegar in the preserving kettle, and add part of the tomatoes; add sugar, spice, ginger, cinnamon, cloves, mace, nutmeg, etc., to taste. Add more of the tomatoes, more sugar and spices; continue these layers until all the tomatoes and 5 pounds of sugar have been used up. Cook very gently, stirring just enough to keep from scorching; do not break the tomatoes; cook until clear and 
transparent; remove carefully, and boil down the syrup until thick; strain it and add the tomatoes; boil up once, and pour into well sterilized pint jars, and seal.

\section{No. 47-Tomato Marmalade}

Use-

4 quarts of ripe tomatoes, peeled and sliced,

6 lemons, cut in halves lengthwise and sliced very thin,

1 cup of seeded raisins.

Put all in a preserving kettle in layers, alternating with 4 pounds of granulated sugar.' Cook one hour on the front of stove. Then set where it will boil very slowly until it is the consistency of marmalade. No one article should be recognizable. Put up while hot, as jelly. This recipe makes about $2 \frac{1}{2}$ quarts. The small yellow, pear, egg, and cherry tomatoes are especially fine put up in this way.

\section{No. 48-Tomato Mock Orange Marmalade (Delicious)}

Scald and peel large-sized, yellow tomatoes; cut downward over each seed section; press open and remove all seeds with the thumb, leaving the pulp comparatively whole. To two parts of the prepared tomatoes allow one part of oranges, sliced thinly. Cover all with an equal quantity of sugar, and let stand over night. In the morning pour off the syrup, and cook down about half; add the tomatoes and oranges, and cook until the orange skins are transparent; seal in jelly glasses.

\section{No. 49-Green Tomato Mince Meat}

Take-

1 peck of green tomatoes put through a meat-chopper,

5 pounds sugar,

3 pounds raisins, seeded,

1 teaspoon cinnamon,

1 teaspoon cloves,

1 teaspoon allspice,

1 teaspoon nutmeg, grated,

$1 / 2$ teaspoon salt,

$1 / 2$ teaspoon black pepper.

After grinding the tomatoes, press the water out, after which add enough boiling water to cover, and boil two hours. Add all the other ingredients, mixing thoroughly. Boil $1 / 2$ hour longer, pour into jars, and seal with paraffin. 


\section{No. 50-Tomato Relish, English Style}

Use-

5 quarts peeled and cut tomatoes,

5 quarts cabbage, finely shredded,

5 quarts small cucumbers, shredded,

5 large cucumbers, shredded,

12 large onions, sliced,

24 small red peppers.

Salt, and let stand over night; drain in the morning, and scald in weak vinegar.

\section{Dressing for Relish}

1 gallon moderately sour vinegar,

5 cups brown sugar,

$1 \frac{1}{2}$ cups flour,

1 pint of made mustard,

1 ounce yellow tumeric.

Mix all and boil until thick; add to the above ingredients, heat boiling-hot, and seal in glass jars or bottles.

No. 51-Tomato and Mustard Pickles

Take-

1 quart of green tomatoes, cut into small pieces,

1 quart of small cucumbers, cut in chunks,

1 quart of small button onions,

4 green peppers, cut fine,

1 red pepper, cut very fine,

1 cup of flour,

6 tablespoons ground mustard,

1 tablespoon tumeric, with enough vinegar to make a paste,

1 cup sugar, and sufficient vinegar to make 2 quarts in all.

Put flour, mustard, tumeric, sugar and vinegar on back of stove and cook until thick. For the cucumbers, onions, tomatoes, and peppers make a brine of 4 quarts of water and 1 pint of salt; let stand in this 24 hours, place on stove, let come to a boil, pour in a colander and drain. Add the vegetables to the mustard mixture, and cooks until it is well heated through. Seal in glass jars.

No. 52-Green Tomato Sweet Pickles (Delicious)

Take-

7 pounds green tomatoes,

4 pounds sugar,

3 quarts vinegar,

1 pound of seeded raisins, Cinnamon, spice, ginger, and cloves to taste. 
Cut the tomatoes in $1 / 2$ inch slices, and soak for 24 hours in a water bucket of cold water, in which is $3 / 4$ of a pint of lime; then soak in cold water for two hours or until there is no taste of the lime. Drain thoroughly, add to the vinegar and spices, boil in the syrup two hours, seal in well sterilized glass jars.

Use-

\section{No. 53-Tomato Chopper Pickles}

$1 / 2$ gallon chopped green tomatoes,

$1 / 2$ gallon shredded cabbage,

1 quart tender beans, sliced,

5 green peppers, chopped fine,

2 bunches of celery, chopped fine,

2 teaspoons ground cinnamon,

2 tablespoons spice,

2 tablespoons cloves,

2 teaspoons white mustard seed,

1 tablespoon salt,

2 tablespoons grated horse radish,

1 tablespoon mace,

2 tablespoons ginger.

Mix all together, and boil 20 minutes; seal in glaș j jars.

\section{No. 54-Tomato Salad}

Select medium sized tomatoes, one for each person to be served; wash, and dry carefully, cut off the stem end of each, and remove the pulp with care; cut the pulp and one whole tomato in small pieces (do not chop), cut one onion in dice, and a small stalk of celery in. small pieces. Mix the onion, tomatoes, and celery together. lightly but thoroughly; stuff the tomatoes with the mixture, and serve on crisp lettuce leaves with a generous spoonful of mayonnaise dressing heaped on each tomato. This is a delicious salad, and very. appetizing in appearance.

\section{No. 55-Tomato Omelet}

Beat 4 eggs very lightly, and add $1 / 4$ cup of flour mixed smooth with a little milk, pepper, and salt to taste, add one cup of finely-chopped tomatoes, either fresh or canned; pour into a hot buttered pan, and fry slowly. When done serve at once on a hot dish. 


\section{No. 56-Tomatoes on Toast}

To a cup of stewed tomatoes that have been well seasoned with butter, pepper, salt, and a little sugar, add the same quantity of chopped ham, one beaten egg, and a little gravy; boil and spread a generous spoonful on each slice of well browned toast; serve hot.

\section{No. 57-Tomato and Cheese Patties}

Moisten a quart of stale bread crumbs with a cupful of stewed tomatoes; add two eggs, one large cupful of grated cheese, a mediumsized onion, minced fine, and a piece of butter the size of a walnut; season with salt and pepper; knead thoroughly; add fine bread crumbs until of the right consistency; mould into patties. Dip in beaten egg, then in crumbs, and fry in hot butter until brown; serve hot.

\section{No. 58-Tomato Catsup, No. 2}

Boil $1 / 2$ bushel of ripe tomatoes until they are soft, press through a sieve, and to the juice add one pint of salt, one ounce of Cayenne pepper, and a little garlic; mix, and boil until reduced one-half; bottle and seal hot.

No. 59-Tomato Salad, No. 2

Use-

3 large tomatoes, cut into small pieces,

1 cucumber, diced,

1 onion, diced,

Make a dressing of:

2 tablespoons olive oil,

1 tablespoon strong vinegar,

1 scant teaspoon salt.

Mix the dressing and pour over the salad just before serving.

\section{No. 60-Tomato Jelly Salad}

Boil two cups of tomatoes; add a teaspoon of brown sugar, a teaspoon of vinegar, and season to taste; strain; add a teaspoon of gelatin dissolved in a quarter of a cup of cold water, and turn into small moulds; serve on lettuce leaves with a boiled dressing.

\section{No. 61-Tomato Novelty Salad}

Take equal parts of ripe tomatoes, sour apples, and celery; cut all into thin shreds;mix thoroughly, and serve with French dressing. 


\section{No. 62-Tomato Butter}

Uับอ-

10 pounds of ripe tomatoes, skinned,

4 pounds granulated sugar,

3 pounds sour apples, sliced fine,

1 quart vinegar,

1 ounce stick cinnamon,

$1 / 2$ ounce ginger,

$1 / 4$ ounce mace,

$1 / 4$ ounce whole cloves.

Put spice in a thin bag; put all the ingredients together, and boil until quite thick, stirring frequently to keep from burning.

\section{No. 63-Savory Tomatoes and Rice}

Use-

6 large tomatoes, peeled and sliced,

2 large sweet peppers, chopped fine,

1 cup cooked rice,

4 tablespoons butter,

Salt and pepper to taste.

Butter a baking dish; put in a layer of tomatoes; sprinkle with sugar, and cover with rice and peppers. Alternate the layers until dish is full, having the tomato on top. Dot with the butter; bake (covered) three-fourths of an hour; uncover and bake for quarter of an hour longer, serve hot.

\section{No. 64-Tomato, Fig, and Nut Salad}

Take-

2 tablespoons blanched peanuts,

2 tablespoons hickory-nut meats,

2 tablespoons pecan meats,

1 cup chopped figs,

2 tablespoons of minced celery.

Chop the nuts very fine; mix in the chopped figs and celery. Remove the stem end of ripe tomatoes, scoop out the centers, drain the pulp, and mix with the nuts; toss all together until well mixed; cover with a cup of mayonnaise dressing. Fill the tomatoes with this mixture; serve on white, crisp cabbage leaves taken from the interior of a head; place the tomatoes in the center of leaves, and garnish with whatever filling is left.

No. 65-Tomato Puree

Use-

2 medium-sized potatoes, 
1 can, or its equivalent of fresh tomatoes,

2 tablespoons of butter (heaped) or a cup of left-over gravy, or two cups of chickeen or beef stock.

Thicken with a tablespoon of flour mixed smooth with cold water; mix all together; season with salt and pepper to taste; cook onehalf hour; serve hot with sippets of toasted bread.

\section{No. 66-Tomatoes Stuffed with Ham}

Scoop out the center of large, firm tomatoes; mix the pulp with some finely-chopped boiled ham that has been seasoned with prepared mustard; add to this mixture one onion, chopped very fine, some chopped parsley and bread crumbs; put back in shells and bake until tender; serve at once.

\section{No. 67-Tomato and Egg on Toast}

Fry a few pieces of bacon; remove from fat; dip into flour thick slices of tomatoes that have been seasoned with salt and pepper, and fry in same fat. Have hot buttered toast ready; place slices of tomatoes on each, with a fried egg on top of each slice of tomato. Arrange the slices of bacon around the sides of the dish.

\section{No. 68-Tomatos Broiled}

Cut firm, well-ripened tomatoes into slices; season, and dip in fine bread crumbs; broil over hot fire; put on a hot platter, and pour over them one cup of white sauce. It may be served on toast if desired.

\section{No. 69-Tomatoes and Bacon}

Toast rounds of bread; sprinkle generously with grated cheese; put a slice of tomato on each round, and two slices of bacon on top of the tomato; bake in quick oven until bacon is crisp.

\section{No. 70-Tomato Salad with Cream}

Peel and slice into a salad bowl, tomatoes in rather thick slices; sprinkle with salt, pepper, and a little sugar if desired; chill, and just before serving put over them a generous amount of whipped cream, and sprinkle with chopped olives; serve at once. 


\section{No. 71-Tomato Timbales}

Boil two cups of canned or stewed tomatoes and one finely-minced onion for five minutes; thicken with a tablespoon of dissolved flour; cool; add three beaten eggs, and fill small buttered moulds; set in a pan of hot water and bake until firm like custard.

\section{No. 72-Tomato Sauce (Mexican Style)}

Take-

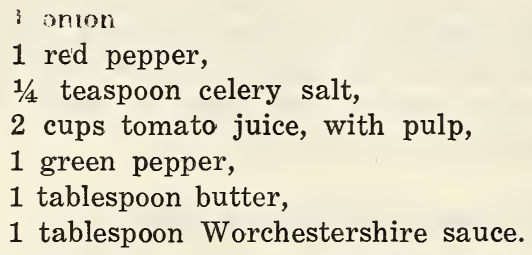

Chop onion: cook for 5 minutes in butter; add peppers, finely chopped then add the tomatoes and seasoning. Simmer for 15 minutes; then put in thin slices of whatever meat you wish.

\section{No. 73-Tomato With Crab Meat}

Use-

1 can of crab meat,

1 cup bread crumbs,

1 cup of tomatoes (stewed),

1 lemon (grated),

1 glass of sherry.

Mix meat with bread crumbs; add all the other ingredients; turn into a dish, and bake from 15 to 20 minutes.

\section{No. 74-Tomato Sauce with Spaghetti}

\section{Use-}

1 can tomatoes, or its equivalent in fresh ones stewed.

$1 / 2$ eup water,

$1 / 2$ teaspoon salt,

1 pinch of black pepper,

1 tablespoon butter,

1 tablespoon flour,

1 tablespoon sugar,

5 tablespoons cheese (chopped fine).

Cook all together for a few minutes. Boil $1 / 4$ package of spaghetti, 
having water boiling and well salted when it is put in; cook until tender; drain off the water, and pour tomato sauce over the top.

\section{No. 75-Tomato Bisque}

Use-

2 cups of tomatoes (boiled 5 minutes),

1 tablespoon butter,

2 tablespoons flour (dissolved in milk),

$1 / 4$ onion, minced fine.

Mix all together and let boil for five minutes; strain and return to the fire; add 3 cups milk, $1 / 2$ cup of cream, $1 / 4$ teaspoon soda, and boil one minute; serve at once.

\section{No. 76-Tomato Soup (St. James' Style)}

Boil 20 minutes 4 cups of tomatoes with one cup of water; strain; add $3 / 4$ cup of cracker dust or fine bread crumbs, a teaspoon of lemon juice, a stalk of celery, salt and pepper to taste; just before serving add to each cup a teaspoon of lemon juice, a thin slice of orange, and a tablespoon of whipped cream.

\section{No. 77-Tomato Hash}

Use-

$11 / 2$ cups bread crumbs,

2 cups tomatoes,

1 cup chopped meat of any kind,

1 tablespoons butter,

1 onion, chopped,

$1 / 2$ cup tender corn, either fresh or canned,

1 tablespoon meat gravy.

Mix thoroughly; fry or bake until brown.

Take-

\section{No. 78-Tomato, Sausage and Spaghetti}

\section{1 quart rich tomato soup,}

$1 / 2$ cup hot water,

$1 / 2$ pound spaghetti,

1 pound sausage.

If the sausages are in cases, nick them thoroughly; place in a frying pan; cover with boiling water, simmer until done and well browned (about an hour). Break the spaghetti in small pieces, and cook in salted water until done; drain; rinse in cold water; drain again; confine the sausage and spaghetti in the frying-pan; 
add the soup diluted with hot water, and let it stand until boilinghot; serve at once.

Take-

\section{No. 79-Tomato Aspic with Tongue}

4 cups fresh or canned tomato juice,

1 cooked tongue,

$1 / 2$ teaspoon beef extract,

1 small onion,

$1 \frac{1}{2}$ teaspoons salt,

6 cloves,

3 tablespoons gelatine,

Pepper to taste.

Simmer together the tomatoes, salt, pepper, onion, and cloves for 20 minutes; add the beef extract and gelatine, which should have been soaked in cold water until soft; wet a mould with cold water, pour in a thin layer of the tomato aspic, and when it is almost set, put in the tongue, which may be whole if nicely trimmed or sliced as desired; add the remaining aspic if the whole tongue is used, or arrange in layers if sliced; continue until all the aspic is used; when firm serve.

\section{No. 80-Tomato and Sardine Salad (Individual)}

1 medium-sized tomato,

1 teaspoon chopped sweet pepper or pimento,

$1 / 4$ teaspoon sugar,

3 sardines,

2 olives,

$1 / 2$ teaspoon chopped onion,

2 teaspoons chopped celery or cabbage,

2 teaspoons mayonnaise,

1 teaspoon shredded lettuce,

$1 / 2$ teaspoon minced parsley.

Cover with mayonnaise (additional); peel the tomato; cut off the top and scoop out the center; mix with one of the olives chopped, the onion, sugar, pepper, celery, and mayonnaise; refill the tomato, and set in a nest of shredded lettuce. Place a spoonful of mayonnaise on top, and sprinkle with the minced parsley; surmount with the other olive, and lean three sardines against the tomato to give a tent-like appearance. 


\section{No. 81-Tomatoes with Puff Balls}

Use-

6 small puff-ball mushrooms,

6 tomatoes,

2 tablespoons butter,

$1 / 8$ teaspoon paprika,

$1 / 2$ teaspoon salt,

3 cups water.

Cut the tomatoes fine, and stew in water 20 minutes; rub through a puree-sieve. Add the puff-balls diced, the salt, and the paprika, and simmer for 10 minutes. Add the butter, and serve very hot. The puff-balls should be about the size of medium potatoes. All varieties are wholesome and delicious if eaten when the flesh is as white as curd.

\section{No. 82-Tomatoes Stuffed with Shrimps}

Take-

6 medium-sized tomatoes,

1 can shrimps, halved,

$1 / 2$ teaspoon minced onion,

2 slices bread, crummed,

$1 / 2$ teaspoon minced parsley,

$1 / 2$ teaspoon green pepper, minced,

$1 / 2$ teaspoon salt,

2 tablespoons butter,

A few grains of paprika.

Add a few more dry, buttered bread-crumbs; cut off the tops of the tomatoes; scoop out the centers; add the other ingredients except the shrimps. Heat the butter boiling-hot; fry the shrimps; then add to the tomatoes; fill the tomatoes with the mixture; dust the tops with the buttered crumbs, and bake 20 minutes in a moderate oven.

\section{No. 83-Tomato Surprise}

Use-

1 large can tomatoes,

1 tablespoon butter,

1 tablespoon flour,

2 hard-boiled eggs,

$11 / 2$ tablespoons sugar,

1 teaspoon salt,

$1 / 8$ teaspoon pepper,

Melt the butter and flour, and stir till dark-brown; turn in the tomatoes, sugar, salt, and pepper; cook till thick (about 30 minutes). Just before serving slice the hard-boiled egg over the top. 


\section{No. 84-Tomato Hors D'Oluvres}

Remove skins from very small, uniform-sized tomatoes; scoop out centers and fill with Roquefort cheese which has been beaten smooth with a little cream; place on round slices of bread which have been toasted and buttered or fried in deep fat; cover tops of tomatoes with caviar; thrust a sprig of cress in the top of each one; arrange on salad plates covered with small paper doilies; garnish further with cress if desired.

\section{No. 85-Tomato and Cucumber Salad}

Select firm, ripe tomatoes; cucumbers to make the same number of slices; half the amount of onions; slice and arrange artistically on crisp lettuce leaves; sprinkle minced green sweet peppers over all; chill; when ready to serve pass French or mayonnaise dressing.

Use-

\section{No. 86-Tomato and Okra Soup}

$1 \frac{1}{2}$ pints of tomatoes pared and cut fine,

2 quarts water,

1 pint sliced okra,

3 tablespoons rice,

3 tablespoons minced onion,

1 green pepper chopped fine (seeds removed),

3 tablespoons salt,

$1 / 4$ teaspoon pepper,

3 tablespcons green corn.

Put all the ingredients into the soup pot, and cook gently for two hours; then add two tablespoons butter or sweet drippings, and serve. The bones from roast meat or broiled meat adds to its flavor.

\section{No. 87-Deviled Tomatoes}

Take-

4 large, firm tomatoes cut into thick slices,

1 tablespoon vinegar,

1 tablespoon mushroom ketchup,

1 scant tablespoon sugar,

$1 / 2$ teaspoon salt,

$1 / 4$ teaspoon dry mustard,

$1 / 2$ toaspoon onion juice,

1 bay leaf,

$1 / 8$ teaspoon paprika.

Mix all the above ingredients; put two tablespoons cotton cooking oil, butter, or lard into a frying-pan, add mixture of seasoning, and 
when hot put in the tomatoes, and cook until tender; serve hot.

\section{No. 88-Tomatoes Baked with Eggs}

Select firm, ripe tomatoes; peel; cut off the stem end; scoop out the center sufficiently to hold a broken egg-do not break the yolk; season with butter, pepper, and salt; cover with buttered bread-crumbs, and bake in a moderate oven until tomatoes are tender. Serve on rounds of buttered toast with cream sauce.

\section{No. 89-Tomatoes with Noodles (Very rich)}

Take 3 pounds of fresh tomatoes (or 1-quart can); peel, season, and cook the same as for tomato sauce.

Noodles. Break two eggs in a bowl; beat, adding a pinch of salt; then work in flour with the hands until the dough is very stiff; turn on board, and work until dough is smooth and shining. Pinch off a piece the size of a hen's egg, and roll out as thin as paper; cut int? very narrow strips with a sharp knife; roll or drop them in as you wish; boil in the tomato sauce until done. If the sauce does not contain sufficient butter add another tablespoon. Cook slowly until done; serve hot. To many tastes the noodles are superior to macaroni or spaghetti.

\section{No. 90-Tomato Omelet}

Take-

6 eggs well whipped,

2 tablespoons flour, mixed until smooth with a little milk, pepper and salt to taste,

4 tomatoes peeled and chopped very fine.

Stir all together, and fry in butter; serve hot.

\section{No. 91-Tomato Hungarian Stew (Very rịch)}

Use-

2 pounds of cheapest cuts of beef cut into small pieces.

1 onion sliced and fried with the meat, in butter or drippings, until the meat begins to turn brown.

Put a layer of the meat in the kettle; cover with a layer of the thinly-sliced onion; continue this way, alternating the layers of meat and onion until all the meat has been used; cover with cold water, and gradually bring to the boiling point. Turn in two cups or its equivalent of canned or fresh tomatoes, but do not stir; simmer for two hours, tightly covered; then add some potatoes cut into thick slices or chunks; salt and pepper to taste; cook until meat is tender, and serve hot. 


\section{No. 92-Tomato Souffle}

Stew down to one pint 3 cups of tomatoes; rub through a sieve; sweeten to taste, and add the beaten yolks of 6 eggs and stifflywhipped whites; bake in a hot oven until set; serve as soon as done.

\section{No. 93-Tomato Higdom}

Take-

1 bushel of green tomatoes chopped fine,

1 cup mustard,

3 pounds sugar,

12 red peppers chopped fine,

$1 / 2$ cup celery seed,

$11 / 2$ cups salt.

Mix the salt with the chopped tomatoes; let stand over night; press hard and drain off all the juice possible. Mix all the other ingredients thoroughly; pack in jars, and cover with boiling-hot vinegar.

No. 94-Tomato Chowder (Extra fine)

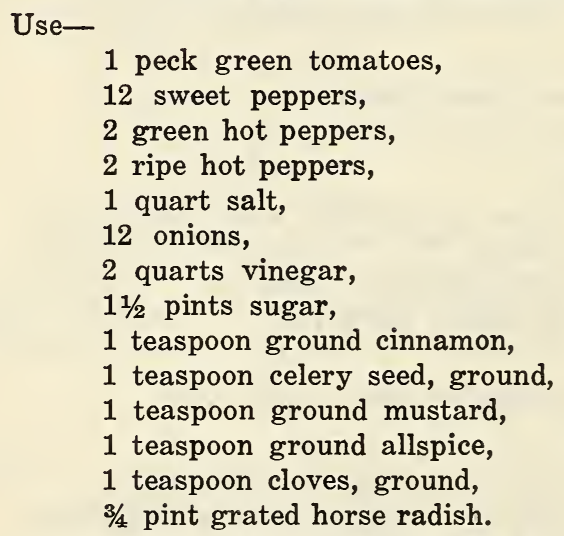

Sprinkle the salt over the chopped tomatoes, peppers, and onions; mix and let stand over night; press out and drain off the water next morning. Mix all the other ingredients thoroughly, and boil for 15 minutes; pack in glass or stone jars; cover with hot vinegar, and seal.

\section{No. 95-Tomatoes Riced}

Take-

1 cup rice,

1 can tomatoes, 
2 cups sour stock or water,

1 tablespoon butter,

Salt and pepper to taste.

Melt the butter in stew kettle; turn in the rice and cook five minutes, stirring all the time; now add the stock, tomatoes and seasoning; boil one-half hour; turn into a baking dish, and bake 25 minutes in a moderate oven; serve hot.

\section{No. 96-Tomato Pot Roast}

Put roast into a suitable pan; pour over it one cup of boiling water; let remain on the stove until it begins to boil; pour over this a large can of well-seasoned tomatoes; bake in a medium oven until done, which will require about three hours.

\section{No. 97-Tomatoes a la Indian}

Cut rounds of bread and saute in butter until brown on both sides; cut ripe, firm tomatoes in thick slices, two for each person; cut into strips a good-sized green tomato; dip in boiling water; drop in ice water. Wipe the tomatoes and fry in hot butter; lay a slice of each on each slice of bread; season well, and sprinkle with pepper and cover with another slice of tomato; garnish with the yelks of hardboiled eggs; put through a ricer with a little parsley.

\section{No. 98-Ripe Tomato Chutney}

\section{Use-}

10 ripe tomatoes, peeled and chopped fine,

6 large green apples, peeled, cored, and chopped fine,

$3 / 4$ pound of raisins, seeded and chopped,

2 red peppers, cored and chopped very fine,

3 onions, medium-sized, chopped fine,

1 pound brown sugar,

3 pints vinegar,

$1 / 2$ cup salt,

2 tablespoons mustard seed.

Place all but the vinegar in an open-mouthed jar; scald the vinegar; when cool pour over the mixture-the vinegar must just cover the mixture-if it does not, scald more and add to it. Stir every day for ten days; then set aside in a cool place until needed for use.

Take-

$$
\text { No. 99-Superior Tomato Pickle }
$$

3 quarts green tomatoes, chopped,

1 quart ripe tomatoes, chopped,

3 small bunches of celery, chopped very fine, 
6 medium-sized onions, chopped,

4 green peppers, chopped,

4 red peppers, chopped,

1 quart small green cucumbers, chopped,

1 large ripe cucumber, chopped,

1 pound cabbage, chopped,

1-3 cup salt,

4 cups brown sugar,

7 cups vinegar,

1 teaspoon mustard,

1 teaspoon black pepper,

1 tablespoon cinnamon,

1 teaspoon ground cloves.

Chop vegetables; sprinkle with salt, and let stand over night; press out the water, and drain in the morning. Mix all the other ingredients; mix thoroughly; pack in small jars; cover with vinegar; and seal. It spoils rather quickly after opening.

\section{No. 100-Tomato Sauce (Commercial style)}

Use $1 / 2$ bushel of ripe tomatoes, washed and mashed to a pulp; put in a porcelain-lined kettle with 2 tablespoons salt; boil until tender; cool, and mash through a sieve. Take $1 / 2$ gallon of the thin juice; add 2 pounds of sugar, one tablespoon each of whole cloves and black pepper, six blades of mace, a short stick of cinnamon, and a root or two of ginger. Let this boil until well flavored with the other spices; then strain, mix with the other juice, and boil until thick; add 1 quart of apple vinegar; boil 15 minutes; bottle and seal. Ordinary fruit jars may be used. Keep in a cool, dark place. It can be used immediately, but improves with age.

\section{No. 101-Green Tomato Preserves (Delicious)}

Use-

1 peck green tomatoes,

7 pounds sugar,

6 lemons, sliced and seeded.

Place in preserving kettle; heat slowly without water; allow to simmer all day, taking care not to let it scorch; when it becomes thick and dark in color add the lemons; put hot into jars, and seal. This is truly delicious; try it.

\section{No. 102-Tomato Mince Meat, No. 2}

Slice up the desired quantity of tornatoes; sprinkle with salt; put in a bag; hang up and allow to drain over night; in the morning take 
equal weights of tomatoes and sugar, and cook until the tomatoes are thoroughly done; to 7 pounds of the mixture of tomatoes and sugar add 3 pounds of seedless raisins, and mace and cinnamon to taste; cook a short time after, adding the seasoning, and put into jars. It will keep without being sealed. It makes delicious pies, more relished by some than ordinary mince-meat.

\section{No. 103-Tomato Mince Meat, No. 3}

Take-

1 peck green tomatoes, chopped fine,

4 pounds brown sugar,

1 pound chopped citron,

1 pound raisins,

1 pound currants,

2 cups chopped suet,

1 teaspoon salt,

2 teaspoons cinnamon,

1 teaspoon cloves,

1 cup vinegar.

Cover the tomatoes with cold water; scald and drain three times (scalding each time 1/2 hour); mix all together; cook until tender; seal in glass jars, and set in a cool, dark place.

\section{No. 104-Tomato Fritters, No. 1}

Rub a pint of tomatoes through a sieve; thicken with 2 tablespoons of corn starch, and add seasoning. Remove from the fire, and add one egg yolk; pour into a shallow pan to cool, then cut into rounds; roll in egg-white and bread crumbs, and fry a golden brown in deep fat.

\section{No. 105-Tomato Fritters, No. 2}

Beat well 1 cup of flour, $1 / 2$ teaspoon salt, a level teaspoon baking powder, a teaspoon melted butter, $2 \mathrm{egg}$ yolks, and $1 / 2$ cup of milk, Add the beaten whites of eggs and 3 tablespoons of tomato pulp. Fry in deep fat and roll in sugar.

\section{No. 106-Tomato Fluff}

Cook one cup of sugar, one cup of strained tomato juice, and the juice of half a lemon to a thick syrup; pour the mixture slowly over the stiffly-beaten white of $1 \mathrm{egg}$; serve at once or chill as desired. 


\section{No. 107-Green Tomato Cream (Delicious)}

Wash and slice four medium-sized green tomatoes; slice thin one sour apple, and add one onion chopped fine. Put two tablespoons of fat in frying-pan and place over fire. When hot scatter in onion and apple, and let fry 5 minutes; then lay on slices of tomatoes that have been sprinkled on either side with flour, salt, and pepper; when brown on both sides pour over two cups of hot sweet milk, and let simmer 5 minutes; serve hot.

\section{No. 108-Green Tomato Pie, No. 1}

Peel the tomatoes, and with a sharp knife slice very thin; proceed as for apple pie; add one cup sugar into which a teaspoon more or less of flour has been added, according to the juiciness of the tomatoes; dot all over sparingly with lemon; cover with top crust; brush with beaten egg or milk; bind edges with muslin, and bake 40 or 45 minutes. This pie is more savory the day after it is baked.

\section{No. 109-Green Tomato Pie, No. 2 (Very rich)}

Slice the tomatoes very thin; sprinkle with lemon juice rather generously; sweeten with brown sugar; dot a tablespoon of butter evenly over the pie; cut some preserved ginger in little bits, and scatter evenly over the pie, also a little chopped lemon peel, and a dusting of cinnamon, after which dredge some flour over the top to keep it from being too juicy, and cover with rich paste. This is said to be a very rich pie.

Use-

\section{No. 110_Tomato Soup with Oatmeal}

1 cup tomatoes, either fresh or canned,

1 cup water,

3 tablespoons rolled oats,

1 scant tablespoon sugar,

1 small onion chopped fine,

$1 / 4$ teaspoon salt,

A dash of pepper.

Put all the ingredients in a sauce-pan together; simmer one-half hour; rub through sieve, re-heat and serve.

\section{No. 111-Tomato Puffs}

Peel and slice well-ripened tomatoes; sprinkle with a little salt and pepper; dust liberally with sugar; dip each slice in rich pancake 
batter( rather thick); fry a rich brown; serve at once.

No. 112-Stewed Tomatoes, Plain

Select the required amount of well-ripened tomatoes; peel; remove hard part of the core; stew gently for 40 or 50 minutes; season to taste with salt, pepper, sugar, and 1 tablespoon buttor; cook 10 minutes longer (uncovered); serve at once.

\section{No. 113-Tomatoes and Beets}

Cook the beets in boiling water until thoroughly done; slice. Prepare enough ripe tomatoes to make an equal number of slices; arrange all in a suitable dish; sprinkle with salt, sugar, pepper, and enough boiling-hot vinegar to cover them; let stand for one hour in a cool place before serving.

\section{No. 114-Tomato Salad (Vienna style)}

Prepare beets the same as for above recipe; for every two slices of beet add one slice of tomato, one slice of cucumber, one small slice of onion; sprinkle each vegetable separately with sugar, pepper, and salt; scald enough vinegar to cover the entire mixture-pour over the vinegar boiling-hot; let stand until cold; arrange all artistically in a salad bowl; pour the vinegar over them; chill for 1 hour, and serve. Mayonnaise or French dressing may be used if desired, instead of the vinegar.

\section{No. 115-Tomato Soy}

Use-

$1 / 2$ peck ripe tomatoes,

1 large pepper, finely shredded,

1 large onion cut in slices,

1 tablespoon ground allspice,

1 tablespoon ground cloves,

1 tablespoon black pepper, ground,

$1 / 4$ cup salt,

1 teaspoon ground mace,

$1 / 2$ pint vinegar.

Boil all together slowly for 1 hour; cool, and bottle for use. 


\section{NOTE}

In the preparation of this bulletin I have used freely the work of many of the very best culinary experts, re-arranging in some instances to suit our particular conditions.

From every source taken, I wish to give my sincere thanks. 